TRUST LOGO HERE

Participant Information Sheet: 12-15 years

<Version 1.1/ 10-OCT-2017 / IRAS 219538>

\title{
QbTest Utility for Optimising Treatment in ADHD (QUOTA)
}

We would like to invite you to take part in our research study. Before you decide, we would like you to understand why the research is being done and what it would involve. Talk to others about the study if you want to, your parents/carers have also been given an information sheet about the study. Please ask if there is anything that is not clear.

\section{What is the project about?}

Some children find it very hard to sit still and finish things. Sometimes doctors give medication to help children be able to focus and we want to help children by making sure doctors know if the medication is doing a good job.

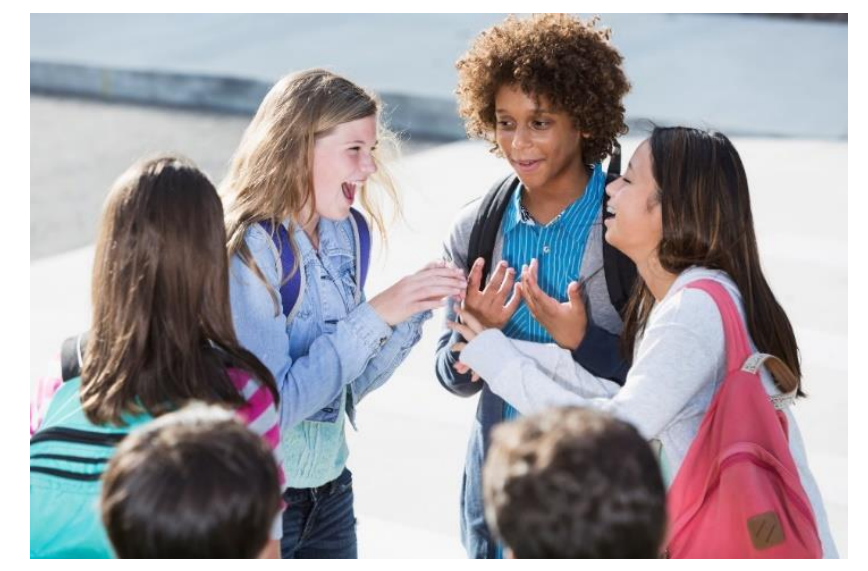

Why have I been asked to take part?

We are asking you to help because your doctor and your family think that medication may help your attention or keeping still when you need to. We will be asking other children and young people like you to help us with the project.

\section{Do I have to take part?}

No. It's up to you. If you do decide to take part your mum or dad or carer will be asked to sign a consent form. Even if your parents/carer wants you to, you can still say no and you won't have to take part. If you don't want to take part, it won't affect your rights and no one will be unhappy with you.

QbTest Utility for Optimising Treatment in ADHD (QUOTA), PIS 12-15yrs, version 1.1, 10-OCT-2017, IRAS 219538. 


\section{What will happen to me if I agree to take part?}

At the beginning of the study the research team will randomly put you into one of two groups.

One group is the 'QbTest group'. If you are in this group your doctor will look after you the way they normally would and you will also be asked to complete a computer task called the 'QbTest'. You will have to complete the computer task 2-3 times in three months.

The other group is the 'standard care group'. If you are in this group your doctor will look after you the way they normally do and you won't do the QbTest computer task. Whichever group you are in, your doctor will look after you.

\section{What is the QbTest?}

The computer task "QbTest" takes 20 minutes to complete. The results of the task will provide you, your parents/carers and your doctor with extra information about your attention, activity and impulsiveness.

If you are in the 'QbTest group' you will be asked to complete the computer task (the QbTest) on two occasions once you have started your medication. You may also be asked to complete the computer task before you start medication. A picture of the task is shown below. When you do the computer task your movements will be measured through a special infra-red camera, this doesn't record any pictures of you. It will just record the movement of a reflective ball that you wear on a headband.

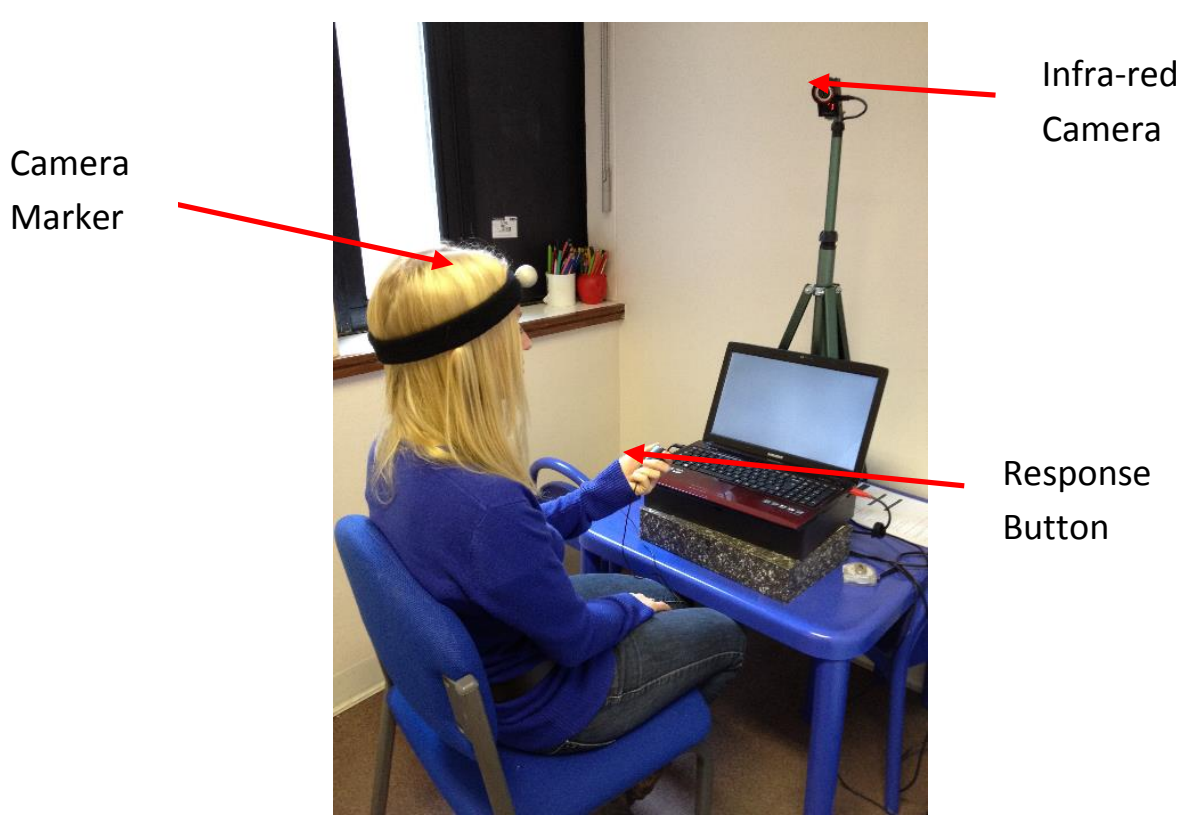

\section{What else does the study involve?}

We would also ask you and your parents/carers and teachers to complete some questionnaires to see how they feel the medication is working. Your parents/carers may ask you to help them complete the questionnaires with them. 
We also really want to know how you found the computer task and how you feel about taking medication so we shall be asking some parents and young people to take part in chats with the research team so we can improve the way we do research in the future.

\section{What are the possible bad bits of taking part?}

You might have to come see your doctor more often to do the QbTest computer task. If you are unhappy about anything that happens in the project, please tell us. You can also tell your mum or dad or carer, or someone who you trust to let us know how you feel.

\section{What are the possible good bits of taking part?}

By taking part, you can help doctors improve the ways they manage your care. You and your parents/carers may also find the results of the computer test (QbTest) interesting. We have conducted previous research using this task and parents and young people often find the results really interesting and are glad they took part.

\section{What will happen if I stop taking part?}

You don't have to take part in the study and you are free to stop at any time, without giving any reason. If you withdraw then the information collected so far might still be used in the project analysis.

\section{Who will know I am taking part?}

The information collected about you will be kept totally confidential. Only the study team will see this information. Any information about you that goes outside of the study will have your name and address removed so that you cannot be recognized from it. Only members of the research team, your doctors and your parents will know that you are taking part in the study.

\section{What will happen to the results of the research project?}

We will write a report about the project once it has finished and your parents/carers will be able to see it and you can too. Your name will not be mentioned in the report.

\section{Contact for further information}

We would like you to chat about this with your parent/carer, but if you want to chat about this some more we would be happy to talk about the study with you. Please contact Charlotte or Maddie:

Charlotte: Tel: 01158232438 ; Email: charlotte.hall@nottingham.ac.uk

Maddie: Tel: 01158230267 ; Email: maddie.groom@nottingham.ac.uk

Names of researchers: Dr Maddie Groom, Dr Charlotte Hall, Dr Julie Clarke, Dr Kim Selby, Dr Sue Brown, Mrs Nikki Brown, Dr Boliang Guo, Dr Kapil Sayal, Prof Chris Hollis. 